\title{
Intramembrane Proteolysis by $\gamma$-Secretase and Signal Peptide Peptidases
}

\author{
Regina Fluhrer and Christian Haass $(\varangle)$
}

\begin{abstract}
The amyloid cascade hypothesis describes a series of cumulative events that are initiated by amyloid $\beta$-peptide and finally lead to synapse and neuron loss. Obviously, the proteases involved in amyloid $\beta$-peptide generation are targets for therapeutic treatment strategies. For the development of a safe therapeutic intervention, however, we must understand the precise physiological functions and the cellular mechanisms involved in substrate recognition, selection and cleavage. Moreover, homologous proteases, whose physiological function could be affected by inhibitors, need to be discovered and assays must be developed to help determine the cross-reactive potential of such inhibitors. Here we will focus on the intramembrane cleavage of the $\beta$-amyloid precursor protein, which is performed by the $\gamma$-secretase complex. In parallel, the cellular and biochemical properties of other proteases belonging to the same family of GxGD-type aspartyl proteases, the signal peptide peptidases and their homologues, will be described. We present a common, multiple intramembrane cleavage mechanism performed by these proteases and evidence that Alzheimer's disease-associated mutations lead to a partial loss of intramembrane proteolysis.
\end{abstract}

\section{Introduction}

Alzheimer's disease (AD) is the most prevalent neurodegenerative disorder worldwide (Hardy and Selkoe 2002). The major pathological hallmarks of the disease are senile plaques, composed of amyloid $\beta$-peptide (A $\beta$; Hardy and Selkoe 2002). $\mathrm{A} \beta$ is generated from the $\beta$-amyloid precursor protein ( $\beta$ APP) by two sequential endoproteolytic steps. While the first cleavage event, which is mediated by

C. Haass

Center for Integrated Protein Science Munich and Adolf-Butenandt-Institute Department of Biochemistry, Laboratory for Neurodegenerative Disease Research Ludwig-Maximilians-University, 80336 Munich, Germany 
$\beta$-secretase, occurs in the hydrophilic environment of either the extracellular space or the lumen of endosomal/lysosomal/Golgi vesicles, the second cleavage, mediated by $\gamma$-secretase, occurs within the hydrophobic environment of cellular membranes. Intramembrane cleavage has been thought to be impossible for quite some time, since it was believed that water molecules, which are absolutely required for proteolysis, are not abundant enough within the hydrophobic bilayer of the membrane. Nonetheless, over the past few years, a number of enzymes have been discovered that share the ability to cleave the transmembrane domain (TMD) of integral membrane proteins (Wolfe and Kopan 2004). These intramembrane cleaving proteases (ICLIPs) are classified according to the amino acid that is localized and required within their catalytically active center. So far representatives of three protease classes have been identified: the site-2 (S2P) metalloprotease (Brown and Goldstein 1999), the GxGD-type aspartyl proteases (Haass and Steiner 2002) and the rhomboid serine proteases (Lemberg and Freeman 2007; Fig. 1).

ICLIP turned out to be an important part of a novel cellular pathway termed regulated intramembrane proteolysis (RIP). RIP describes the sequential processing of an increasing number of single-pass transmembrane proteins, which as a first step

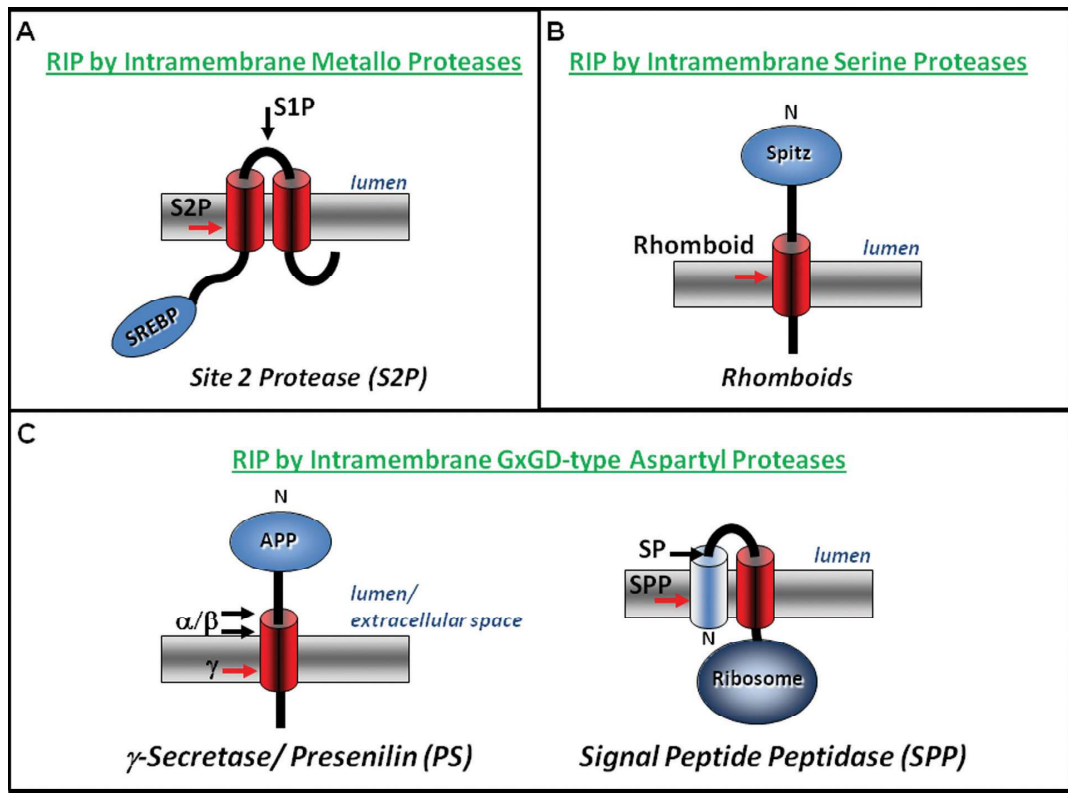

Fig. 1 Models showing regulated intramembrane proteolysis (RIP) by the different classes of intramembrane cleaving proteases. The initial shedding event is marked by a black arrow; the intramembrane cleavage is illustrated by a red arrow. (A) RIP of SREBP involving the intramembrane cleaving metallo protease S2P. (B) RIP of the Drosophila melanogaster protein Spitz involving Rhomboid, an intramembrane cleaving serine protease. (C) RIP of $\beta$ APP and signal peptides involving $\gamma$-secretase and SPP, respectively. $\gamma$-Secretase and SPP are representatives of GxGD-type intramembrane cleaving aspartyl proteases 
undergo a shedding event, removing large parts of their ectodomain. The remaining membrane-bound stub is subsequently cleaved by an ICLIP within its hydrophobic TMD, releasing small peptides to the extracellular space as well as to the cytosol. Cytosolic peptides, the intracellular domains (ICDs), are in some cases translocated to the nucleus and can be involved in nuclear signaling and transcriptional regulation (Haass 2004; Wolfe and Kopan 2004).

All currently known ICLIPs are polytopic proteins, with their active center most likely embedded within certain TMDs. Apparently this enables these proteases to form water-penetrated cavities, allowing proteolysis within the lipid bilayer of cellular membranes (Feng et al. 2007; Lazarov et al. 2006; Lemberg and Freeman 2007; Steiner et al. 2006).

$\mathrm{S} 2 \mathrm{P}$ is required for the regulation of cholesterol and fatty acid biosynthesis via the liberation of the membrane-bound transcription factor, sterol regulatory element binding protein (SREBP), by intramembrane proteolysis. In addition, S2P is involved in intramembrane processing of ATF6, a protein required for chaperone expression during unfolded protein response. Prior to intramembrane cleavage, both substrates are first shed by a luminal cleavage via site-1-protease (S1P; Rawson et al. 1997; Ye et al. 2000; Fig. 1).

A member of the rapidly growing family of rhomboid proteases was first identified in Drosophila melanogaster and was shown to be the primary regulator of epidermal growth factor (EGF) receptor signaling via the processing of Spitz, Karen and Gurken (Lemberg and Freeman 2007; Fig. 1). Besides their function in EGF, receptor signaling rhomboids are also involved in many other cellular pathways, including apoptosis, generation of a peptidic quorum sensing signal in procaryots, invasion of parasites, and mitochondrial fusion (Lemberg and Freeman 2007). Highresolution structures of bacterial rhomboid proteases have recently provided insight into the mechanism of intramembrane proteolysis by serine ICLIPs (Ben-Shem et al. 2007; Lemieux et al. 2007; Wang et al. 2006b; Wu et al. 2006). An intramembranous active site Ser-His dyad as well as the presence of water within a hydrophilic cavity formed by the TMDs have been demonstrated (Lemberg and Freeman 2007). This finding therefore provided the ultimate and unequivocal proof that proteolysis within the hydrophobic bilayer of the membrane is possible. Interestingly, the family of rhombiod proteases seems to be the only ICLIP class that does not necessarily require an initial shedding event preceding the intramembrane cleavage.

The class of GxGD-type aspartyl proteases (Fig. 1) so far covers three ICLIP families, the presenilins (PS), known to be involved in the pathogenesis of AD, the family of signal peptide peptidase (SPP) and SPP-like proteases (SPPL), and the family of bacterial type IV prepelin peptidases (TFPPs; Friedmann et al. 2004; LaPointe and Taylor 2000; Ponting et al. 2002; Steiner et al. 2000; Weihofen et al. 2002).

The PS and SPP/SPPL families share a lot of similarities, but fundamental differences regarding their localization, their molecular composition and their cellular function have also been recently discovered. 

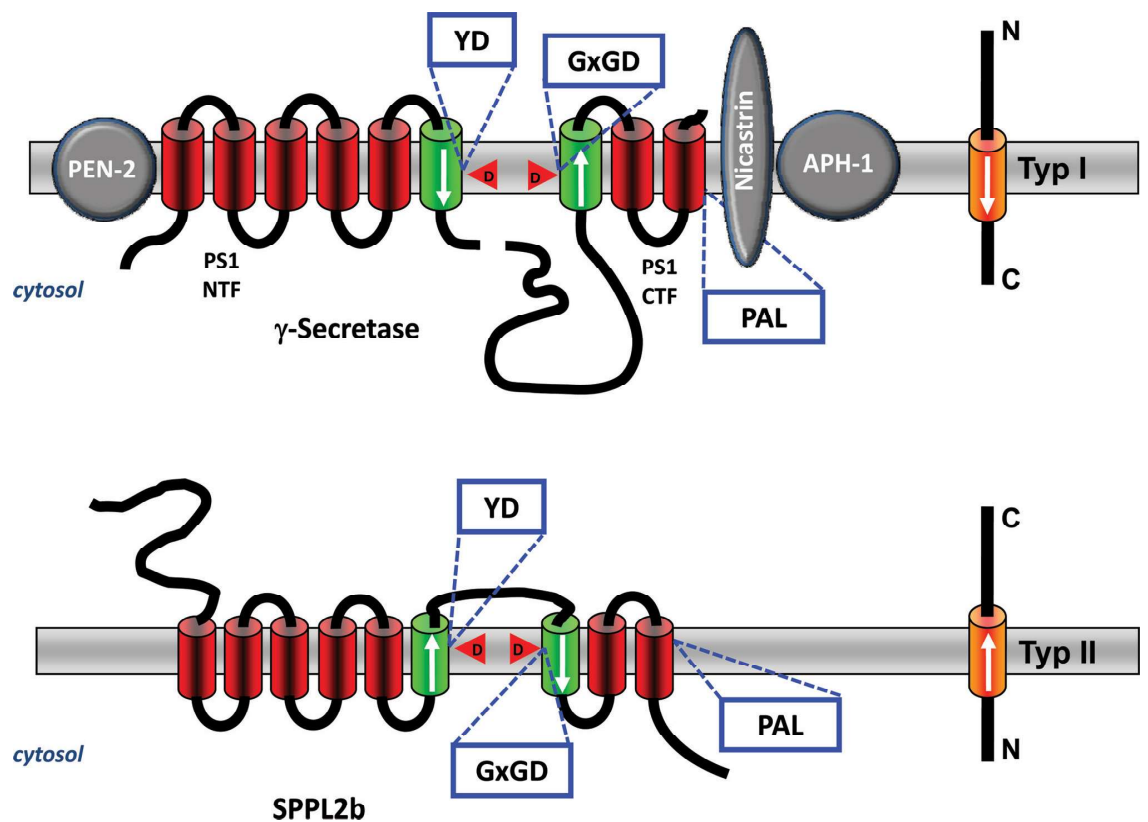

Fig. 2 Model depicting the $\gamma$-secreatse complex and SPPL2b and the orientation of their substrates. The conserved motifs contributing to the active site of the proteases are highlighted. Note that the active site domains of the two enzymes are oriented in exactly the opposite way

In this chapter we will compare the biochemical, functional and structural properties of these protease families with a strong focus on $\mathrm{AD} \gamma$-secretase and SPPL2b, the best-characterized member of the SPPL subfamily (Fig. 2).

\section{Structural and Molecular Organization of Intramembrane Cleaving GxGD-type Aspartyl Proteases}

Although PSs were the founding members of the class of GxGD-type aspartyl proteases, they turned out to be the most complicated family. While the PSs, which provide the active center of $\gamma$-secretase, are members of a high molecular weight complex (Haass and Steiner 2002), SPP/SPPLs and TFPPs seem to act as dimers or even only monomers (LaPointe and Taylor 2000; Weihofen et al. 2002). In addition to PS, the $\gamma$-secretase complex contains three other essential integral membrane proteins: nicastrin (NCT), anterior pharynx defective 1 (APH-1) and presenilin enhancer 2 (PEN-2; Francis et al. 2002; Goutte et al. 2002; Fig. 2). NCT, a $\sim 100 \mathrm{kDa}$ type I transmembrane glycoprotein carrying a large ectodomain and a short cytoplasmic domain (Yu et al. 2000), probably serves as $\gamma$-secretase substrate receptor (Shah et al. 2005). PEN-2 is required for the stabilization of the 
autocatalytically generated PS fragments (Thinakaran et al. 1996) in the complex (Hasegawa et al. 2004; Prokop et al. 2004), whereas the function of APH-1 is still unclear. Together with the $\sim 50 \mathrm{kDa}$ PS, the components form a complex of roughly $500 \mathrm{kDa}$, implying that each component may be represented twice within the complex. Whether $\gamma$-secretase indeed needs to form a dimer to be active or whether a single complex by itself provides proteolytic activity is currently under debate (Sato et al. 2007). The absolute requirement of these four components to form an active $\gamma$-secretase complex was proven by the reconstitution of $\gamma$-secretase in yeast (Edbauer et al. 2003). Only upon expression of all four $\gamma$-secretase complex components is proteolytic activity achieved; overexpression of PS alone is not sufficient. In contrast, to obtain increased SPP/SPPL activity, it is sufficient to simply overexpress the protease (Fluhrer et al. 2006; Friedmann et al. 2006; Nyborg et al. 2004a), indicating that SPP/SPPLs do not need any other essential co-factors for proteolytic activity (Fig. 2). There is evidence that SPP as well as SPPLs form homodimers (Friedmann et al. 2004a, b). The homodimer was selectively labeled by an active site inhibitor, strongly supporting the notion that dimerization is required for biological activity. However, in a later study using a different inhibitor, selective labeling of the monomer was observed (Sato et al. 2006). Whether SPP/SPPLs under physiological conditions have additional transient interactors positively or negatively regulating their proteolytic activity needs to be investigated. For $\gamma$-secretase, CD147 and TMP21 are proposed to fulfill such a regulatory activity (Chen et al. 2006; Zhou et al. 2005), although a very recent observation suggests that CD147 does not directly interact with $\gamma$-secretase but rather modulates extracellular degradation of A $\beta$ (Vetrivel et al. 2008).

While SPP/SPPLs are active as full-length proteins, PS undergoes endoproteolysis (Thinakaran et al. 1996). This endoproteolytic cleavage is most likely an autoproteolytic event (Edbauer et al. 2003; Wolfe et al. 1999); however, this has not been directly proven.

The catalytic center of GxGD-type aspartyl proteases contains two critical aspartate residues located within the two neighboring TMDs 6 and 7 of the protein (Fig. 2). The N-terminal catalytically active site aspartate is embedded in a conserved YD motif, whereas the C-terminal active site domain contains the equally conserved GxGD motif (Steiner et al. 2000; Wolfe et al. 1999). While the catalytic motifs of PSs and SPP/SPPLs are likely located within the hydrophobic core of TM6 and TM7, the active site of the bacterial TFFPs is most likely located at the cytoplasmic border and probably not within the membrane (LaPointe and Taylor 2000). Mutagenesis of either critical aspartate residue in PSs, SPP and TFFPs abolishes their proteolytic activity (LaPointe and Taylor 2000; Weihofen et al. 2002; Wolfe et al. 1999). In zebrafish, expression of GxGD aspartate mutants of SPP/SPPLs phenocopy a morpholino-mediated, knockdown phenotype of the respective SPP/SPPL family member (Krawitz et al. 2005). The formal proof of the requirement of the aspartate within the YD motif of SPPL family members is still missing. The glycine directly N-terminal to the aspartate within the GxGD motif is also required for proteolytic activity of GxGD-aspartyl proteases. In PS1 and SPPL2b, the only other amino acid tolerated at this position is an alanine. Nonetheless the substrate 
conversion of SPPL $2 b$ carrying the G/A mutation is significantly slower compared to the wt enzyme (Fluhrer and Haass, unpublished data). PS carrying the G/A mutation strongly affects the $A \beta 42 / 40$ ratio by selectively lowering $A \beta 40$ production (Steiner et al. 2000; Fluhrer and Haass, unpublished data). The function of the Y within the YD motif of SPP/SPPLs and TFPPs has not been investigated so far, but it is known that, for example, the mutation YD/SD in PS1 causes early onset familial AD (FAD) (Miklossy et al. 2003 and www.molgen.ua.ac.be/ADMutations). So it is tempting to speculate, that like the glycine in close vicinity to the aspartate in the GxGD motif, the tyrosine in the YD motif is required for proper function of the enzyme. At least in PSs and SPP/SPPL family members, a third highly conserved motif, likely to contribute to the active center of GxGD-type aspartyl proteases, is found. The so-called PAL sequence is located in the most C-terminal TMD of GxGD-type aspartyl proteases. The important participation of the PAL motif in the catalytic center is supported by the finding that a transition-state analog inhibitor fails to bind to SPP and PS upon mutagenesis of the PAL sequence (Wang et al. 2006a). It is currently unknown how the PAL domain affects PS and SPP activity; however, one may assume a close proximity of the TMDs.

\section{Cellular Localization}

Originally it was believed that PSs were exclusively localized to early secretory compartments like the ER and the intermediate compartment (Annaert and De Strooper 1999; Cupers et al. 2001). These findings created a large debate in the field, since $\gamma$-secretase activity per se was believed to take place at the cell surface (Haass et al. 1993). This phenomenon is known in the literature as the "spatial paradox" (Checler 2001; Cupers et al. 2001). With the identification of Nicastrin as a component of the $\gamma$-secretase complex (Yu et al. 2000), it was shown that the $\gamma$-secretase complex assembles in the ER and is then targeted through the secretory pathway, where Nicastrin becomes endoglycosidase H-resistant (Kaether et al. 2002). Cell-surface biotinylation assays and live cell microscopy further demonstrate that a small but fully active amount of $\gamma$-secretase is localized to the cell surface (Kaether et al. 2002), whereas a majority of unincorporated PS1 is retained in the ER (Capell et al. 2005; Kaether et al. 2004). Recently, a first protein factor, namely Rer1 (Retention in the endoplasmic reticulum 1), was shown to be required for $\gamma$-secretase complex formation or retention of PEN-2 within the ER (Annaert et al. 1999; Kaether et al. 2007).

SPP is exclusively detected in the endoplasmic reticulum (ER; Friedmann et al. 2006; Krawitz et al. 2005; Fig. 3), accompanied by the substrate preference of SPP that cleaves signal peptides of proteins translated into the ER (Weihofen et al. 2002). Interestingly, although sharing a high sequence homology, SPP and SPPLs localize to different cellular compartments (Fig. 3). SPPL2a and b accumulate on the plasma membrane and within endosomal/lysosomal compartments (Friedmann et al. 2006; Krawitz et al. 2005; Fig. 3). SPPL3 has been detected in the ER (Krawitz et al. 


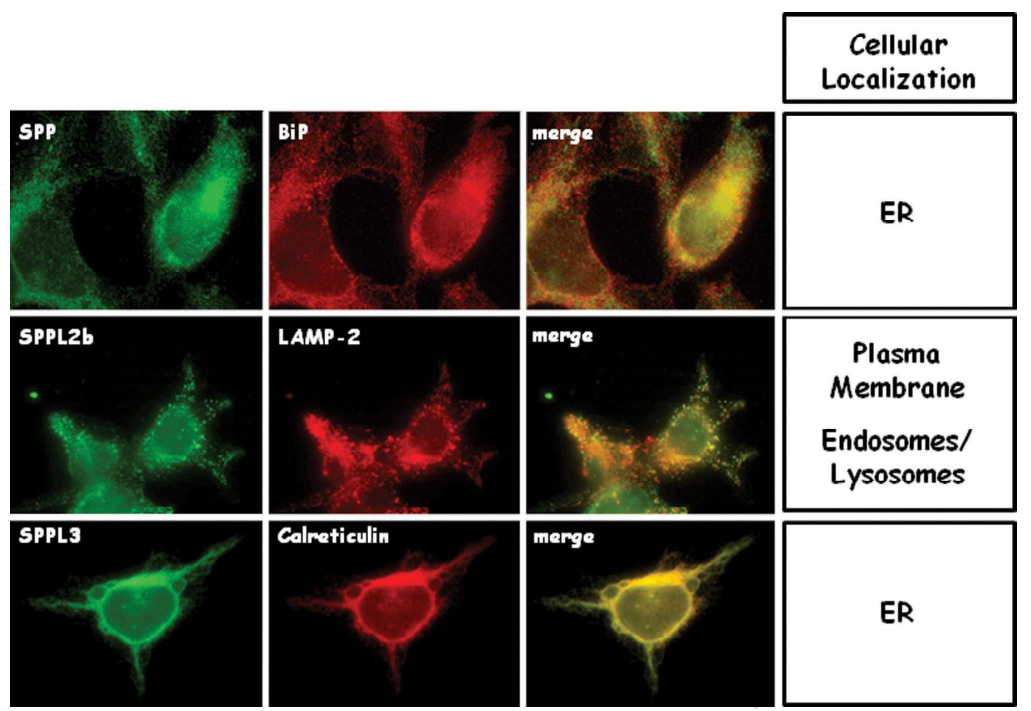

Fig. 3 Differential localization of SPP/SPPL family members. Immunofluorescence staining of SPP, SPPL2b and SPPL3 reveals endoplasmic reticulum (ER) localization for SPP and SPPL3; SPPL2b predominantly localizes to later secretory compartments, including endosomes/lysosomes

2005; Fig. 3) as well as within later compartments (Friedmann et al. 2006). Since SPP only cleaves substrates located in the ER membrane (Lemberg and Martoglio 2002; Weihofen et al. 2002) and all known substrates for SPPL2a and SPPL2b are targeted to the cell surface (Fluhrer et al. 2006; Friedmann et al. 2006; Kirkin et al. 2007; Martin et al. 2008), the substrate selection of SPP/SPPLs may be achieved by their differential subcellular localization. How the distinct cellular localization of SPP/SPPLs is achieved is not yet entirely clear, but SPP may be actively retained within the ER by its putative KKXX retention signal (Weihofen et al. 2002), which is not present in any of the members of the SPPL family.

\section{Substrate Requirements and Physiological Function}

Members of the SPP/SPPL family apparently only accept single pass transmembrane proteins of type II orientation as substrates, whereas PSs exclusively recognize type I trans-membrane proteins (Fig. 2). Since both protease families seem to have numerous substrates, it is discussed that GxGD-type aspartyl proteases fulfill the function of a so-called membrane proteasome (Kopan and Ilagan 2004), removing the sticky transmembrane domains from the cellular membranes that are left behind after proteolytic processing of transmembrane proteins, e.g., shedding of ligands or receptors at the cell surface. How PSs and SPP/SPPLs are able to 
discriminate between type I and type II substrates is currently not fully understood. Strikingly, the active site domains in PSs and SPP/SPPLs are predicted to be arranged in exactly opposite orientations (Weihofen and Martoglio 2003; Fig. 2), which might reflect the opposite orientation of the substrates. Another possibility for substrate discrimination is the receptor proteins or domains within the $\gamma$-secretase complex and SPP/SPPL. The initial recognition of $\gamma$-secretase substrates requires the main part of the substrate ectodomain to be removed by shedding. The $\gamma$-secretase substrates are then recognized by NCT, which identifies the free $\mathrm{N}$ terminus of the substrate (Shah et al. 2005). Therefore. shedding is a prerequisite for every physiological $\gamma$-secretase substrate. Since SPP/SPPLs do not require any co-factors for activity (Fig. 2), the receptor for substrate recognition must be located within SPP/SPPLs themselves, but a defined domain for the substrate recognition has not yet been identified. Maybe the active site itself is involved in substrate recognition, as has recently been shown for PS1, where the active site domain overlaps with a second substrate recognition site (Kornilova et al. 2005; Yamasaki et al. 2006). Shedding of type-II proteins seems to greatly facilitate intramembrane proteolysis of SPPL substrates. In contrast to $\gamma$-secretase substrates, shedding is not an absolute prerequisite for intramembrane proteolysis (Martin, Fluhrer and Haass, unpublished data). This may reflect the absence of NCT as a docking protein involved in substrate identification.

SPP predominantly cleaves signal peptides that are removed from the nascent protein chain by signal-peptidase (SP) in the ER (Fig. 1), in the middle of their hydrophobic core. All signal peptides adopt a type II orientation during co-translation and are therefore, in principle, preferred substrates of SPP (Weihofen et al. 2002). But although a variety of signal peptides from human and viral proteins - like the hormone prolactin, MHC class I molecules and calreticulin - are cleaved by SPP, examples of signal peptides that are not substrates for SPP, like that of RNAse A and human cytomegalovirus glycoprotein UL40, have been published (Lemberg and Martoglio 2002). Therefore, another protease with SPP function might exist, at least in humans. Potential candidate proteins would be the SPP homologues, SPPL3 and SPPL2c, which may both localize to the ER (Friedmann et al. 2006; Krawitz et al. 2005). But so far no substrates have been described for these proteases. Interestingly, however, the knockdown phenotypes of the SPP and the SPPL3 homologue in zebrafish result in virtually indistinguishable phenotypes (Krawitz et al. 2005), which might point to a similar cellular function for the two proteases.

The best-understood $\gamma$-secretase substrates are $\beta$ APP and the Notch-receptor, Notch 1. Although the intramembrane proteolysis of $\beta$ APP contributes to the production of $\mathrm{A} \beta$ (Fig. 4) and therefore to the pathogenesis of $\mathrm{AD}$, the intramembrane proteolysis of Notch 1 is of much greater physiological relevance. This is reflected by the fact that ablation of PS1/2 and other $\gamma$-secretase complex components in many different organisms results in a lethal Notch phenotype (Selkoe and Kopan 2003). The Notch receptors are known to bind ligands like Serrate and Jagged on the cell surface (Selkoe and Kopan 2003). Upon ligand binding, the receptor/ligand-complex starts being endocytosed by the ligand-expressing cell, inducing shedding of the receptor by ADAM proteases (Gordon et al. 2007). On the 

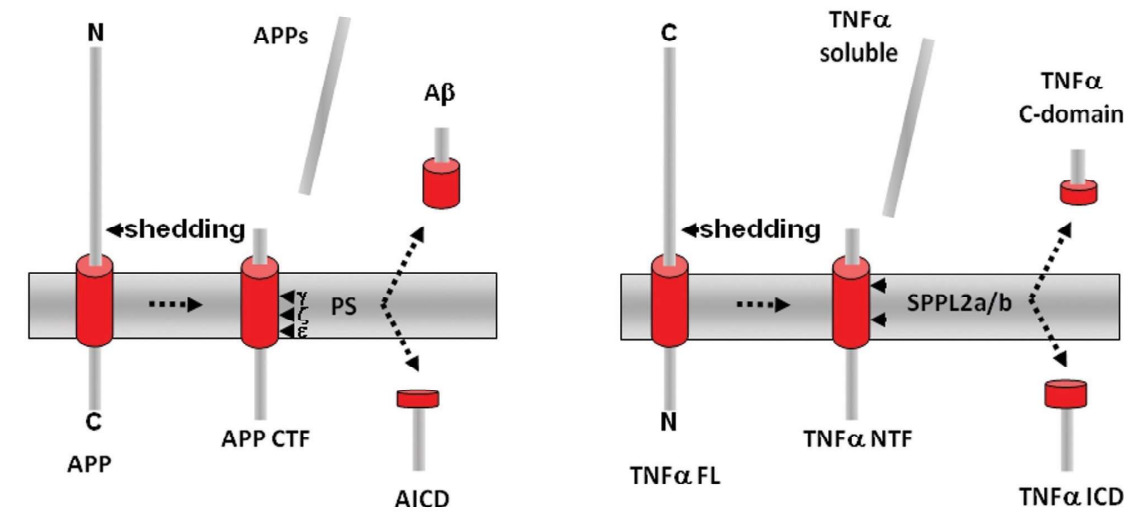

cytosol

Fig. 4 Model showing RIP of APP and TNF $\alpha$. The individual cleavage products after shedding and intramembrane proteolysis are depicted

receptor-expressing cell, $\gamma$-secretase cleaves the remaining stub of the Notch receptor, liberating the Notch ICD, which has been shown to translocate to the nucleus regulating gene transcription (Selkoe and Kopan 2003).

Recently, tumor necrosis factor $\alpha$ (TNF $\alpha$; Fluhrer et al. 2006; Friedmann et al. 2006), the FAS ligand (FasL; Kirkin et al. 2007) and Bri2 (Itm2b; Martin et al. 2008) have been identified as substrates for intramembrane proteolysis by SPPL2a and SPPL2b. All three substrates, like Notch and APP, undergo shedding by a protease of the ADAM family (Fluhrer et al. 2006; Friedmann et al. 2006; Kirkin et al. 2007; Martin et al. 2008). TNF $\alpha$ is a well-known, pro-inflammatory cytokine that has a critical role in autoimmune disorders such as rheumatoid arthritis and Crohn's disease (Locksley et al. 2001; Vassalli 1992). These effects are mediated by the ectodomain of TNF $\alpha$ (TNF $\alpha$ soluble), which is released by TACE/ADAM17 from the cell surface of the TNF $\alpha$-expressing cell (Hooper et al. 1997; Schlondorff and Blobel 1999; Fig. 4). The TNF $\alpha$ ectodomain then enters the blood stream (Gearing et al. 1994; McGeehan et al. 1994) and binds to a variety of different receptors on the signal-receiving cell, triggering the respective signal cascade. In the signalsending cell, the TNF $\alpha$ stub (TNF $\alpha$ NTF) is left behind (Fig. 4). This TNF $\alpha$ NTF is substrate to intramembrane proteolysis by SPPL2a and SPPL2b (Fluhrer et al. 2006; Friedmann et al. 2006), releasing a short TNF $\alpha$ ICD to the cytosol and the corresponding part, the $\mathrm{TNF} \alpha \mathrm{C}$-domain, to the extracellular/luminal space of the cell (Fluhrer et al. 2006; Fig. 4). The ICD of TNF $\alpha$ has been shown to stimulate expression of interleukin-12 in the signal-sending cell (Friedmann et al. 2006), a mechanism that is referred to as TNF $\alpha$ backward signaling. Similarly, the ICD of the FasL translocates to the nucleus, where it may act as a suppressor of gene 
transcription (Kirkin et al. 2007). No physiological function has yet been assigned for the corresponding Bri2 ICD.

Interestingly, a variety of the RIP substrates, like APP, Bri2 and TNF $\alpha$, have been shown to dimerize or even trimerize (Kriegler et al. 1988; Munter et al. 2007; Tsachaki et al. 2008). The dimerization of APP and Bri2 is mediated by GxxxG dimerization motifs (Munter et al. 2007; Tsachaki et al. 2008) that,, when disrupted, lead to altered intramembrane cleavage, at least in the case of APP (Munter et al. 2007). However, the precise mechanism of how the GxxxG motif triggers intramembrane proteolysis is currently unclear.

\section{Cleavage Mechanism}

Mostly, all TMDs of RIP substrates are predicted to adopt an $\alpha$-helical confirmation. Therefore, it is likely that the TMDs require unwinding prior to the occurrence of endoproteolysis. For SPP substrates, this is proposed to be promoted by helixbreaking residues within the hydrophobic core of the signal peptides (Lemberg and Martoglio 2002). Mutation of such residues in the TMD of TNF $\alpha$, on the other hand, does not significantly affect intramembrane proteolysis by SPPL2b (Fluhrer and Haass, unpublished data). Unfortunately, structural information is not available for any of the human SPP family members. Therefore, it is difficult to predict how exactly the intramembrane cleavage is mechanistically performed. However, the $\mathrm{N}$-terminus of the secreted TNF $\alpha \mathrm{C}$-domain and the C-terminus of the TNF $\alpha$ ICD do not exactly match, but are rather separated by 10-15 amino acids (Fluhrer et al. 2006; Fig. 4). Maybe the unwinding of the $\alpha$-helical substrate conformation is facilitated by multiple cleavage events, which step by step open the $\alpha$-helix like an elastic spring. Consequently, these multiple cleavage events allow efficient release of hydrophobic TMDs from cellular membranes. If such multiple cleavages occur with other SPP/SPPL substrates as well is currently unknown. However, a synthetic substrate for SPP has been shown to undergo one major as well as several other minor intramembrane cuts (Sato et al. 2006). Like for TNFo, multiple cleavage events have been reported specifically for the $\gamma$-secretase substrates APP and Notch (Fluhrer et al. 2008), further supporting the idea of unwinding the $\alpha$-helix of the substrate with every individual cleavage. Once the substrate has accessed the catalytic site of $\gamma$-secretase, it is cleaved within its TMD at three topologically distinct sites, termed $\varepsilon$-, $\zeta$ - and $\gamma$-sites (Haass and Selkoe 2007). In the case of APP, the first cleavage at the $\varepsilon$-site releases the APP intracellular domain (AICD; Fig. 4) into the cytosol. The remaining part of the APP TMD is further cleaved at the $\zeta$ - and $\gamma$-sites until $A \beta$ is short enough to be released from the membrane (Fig. 4). Interestingly, the cleavages at the $\varepsilon$-, $\zeta$ - and $\gamma$-sites are heterogeneous, suggesting the existence of two different product lines, leading to the benign $A \beta 40$ on the one hand and to the pathogenic $A \beta 42$ on the other hand (Qi-Takahara et al. 2005). The pathogenic product line generating $A \beta 42$ seems to be dominant in some but not all PS FAD mutants (Qi-Takahara et al. 2005). FAD mutations seem to directly or indirectly affect the 
confirmation of the active site of $\gamma$-secretase, selectively slowing the product line leading to the benign $A \beta 40$ and therefore causing a relative increase of the pathologic A $\beta 42$, leading to early onset AD (Fluhrer and Haass, unpublished data). When a FAD mutation was transferred to the corresponding site in SPPL2b, the sequential cleavage of TNF $\alpha$ was similarly slowed (Fluhrer and Haass, unpublished data). However, the precise mechanism of sequential processing by intramembrane GxGD aspartyl proteases is still unclear.

\section{Inhibition of Intramembrane Cleaving Aspartyl Proteases: a Therapeutic Target}

Since substrates of intramembrane proteases are frequently involved in the development of diseases (see above), the proteases processing these substrates are drug targets. Inhibition of $\gamma$-secretase activity, for example, is an important approach for therapeutic treatment of AD and $\gamma$-secretase inhibitor identification and development reaches an advanced state (Churcher and Beher 2005). Unfortunately, $\gamma$-secretase inhibitors not only block the processing of APP, avoiding the production of $A \beta$, but also interfere with Notch signaling. Therefore, $\gamma$-secretase inhibitors affect cellular differentiation and cause severe side effects. Moreover, active site $\gamma$-secretase inhibitors have been shown to cross react with SPP (Iben et al. 2007; Weihofen et al. 2003) and are likely to also block the members of the SPPL family, since the active site of the GxGD proteases is highly conserved.

Therefore, the development of selective inhibitors is a major challenge for the pharmaceutical industry and academic institutions. Besides synthetic $\gamma$-secretase inhibitors, a very well-known class of non-steroidal anti-inflammatory drugs (NSAIDs) has been shown to selectively decrease cleavage of $\gamma$-secretase at the $\gamma-42$ site of APP without affecting cleavage at the $\gamma-40$ and the $\varepsilon$-site (Weggen et al. 2001). Thus NSAIDS do not affect the $\gamma$-secretase-mediated release of NICD from Notch (Weggen et al. 2001). Whether these NSAIDs directly bind $\gamma$-secretase or APP is currently under debate (Beher et al. 2004; Takahashi et al. 2003). Interestingly, NSAIDs also seem to affect the proteolytic activity of SPP (Sato et al. 2006), either pointing to a direct binding to the enzyme or to a more general mechanism, such as an effect on the lipid composition of the membrane and, therefore, indirectly affecting the conformation of GxGD proteases.

\section{Conclusions}

We have described and compared the biochemical and cellular properties of GxGDtype aspartyl proteases. Although we observed some fundamental differences in terms of substrate recognition and orientation, as well as the requirement of shedding and the role of essential co-factors, the molecular mechanisms of intramembrane 
proteolysis appear to be surprisingly similar. Multiple intramembrane cleavages are performed to release small peptides and to finally remove the TMD from the cellular membranes. FAD-associated mutations affect the kinetics of these intramembrane cleavages. In the case of APP processing specifically, the production of the benign $A B 40$ is reduced whereas the generation of the neurotoxic $A \beta 42$ remains unaffected. A similar partial loss of function was observed when a FAD-like mutation occurring in PS1 was introduced at a homologous position of SPPL2b. Our findings, therefore, finally provide a solution for the long-lasting debate over whether PS mutations cause a loss or a gain of function. Based on the evidence presented, these mutations cause a partial loss of function. This finding may have important therapeutic implications, since treatment of patients with low concentrations of $\gamma$-secretase inhibitors (used to avoid an inhibition of Notch signaling) may lead to a selective reduction of $\mathrm{A} \beta 40$ and thus increase the $\mathrm{A} \beta 42 / 40$ ratio. Moreover, care must be taken to avoid cross-reactivity of $\gamma$-secretase inhibitors with the homologous SPP/SPPL.

Acknowledgements This work is supported by the Deutsche Forschungsgemeinschaft (Gottfried Wilhelm Leibniz-Award (to C.H.) and HA 1737-11 (to C.H. and R.F.) and the NGFN-2. The LMU excellent program supports C.H. with a research professorship.

\section{References}

Annaert W, De Strooper B (1999) Presenilins: molecular switches between proteolysis and signal transduction. Trends Neurosci 22: 439-443

Annaert WG, Levesque L, Craessaerts K, Dierinck I, Snellings G, Westaway D, George-Hyslop PS, Cordell B, Fraser P, De Strooper B (1999) Presenilin 1 controls $\gamma$-secretase processing of amyloid precursor protein in pre-golgi compartments of hippocampal neurons. J Cell Biol 147: 277-294

Beher D, Clarke EE, Wrigley JD, Martin AC, Nadin A, Churcher I, Shearman MS (2004) Selected non-steroidal anti-inflammatory drugs and their derivatives target gamma-secretase at a novel site. Evidence for an allosteric mechanism. J Biol Chem 279: 43419-43426

Ben-Shem A, Fass D, Bibi E (2007) Structural basis for intramembrane proteolysis by rhomboid serine proteases. Proc Natl Acad Sci USA 104: 462-466

Brown MS, Goldstein JL (1999) A proteolytic pathway that controls the cholesterol content of membranes, cells, and blood. Proc Natl Acad Sci USA 96: 11041-11048.

Capell A, Beher D, Prokop S, Steiner H, Kaether C, Shearman MS, Haass C (2005) Gammasecretase complex assembly within the early secretory pathway. J Biol Chem 280: 6471-6478

Checler F (2001) The multiple paradoxes of presenilins. J Neurochem 76: 1621-1627

Chen F, Hasegawa H, Schmitt-Ulms G, Kawarai T, Bohm C, Katayama T, Gu Y, Sanjo N, Glista M, Rogaeva E, Wakutani Y, Pardossi-Piquard R, Ruan X, Tandon A, Checler F, Marambaud P, Hansen K, Westaway D, St George-Hyslop P, Fraser P (2006) TMP21 is a presenilin complex component that modulates gamma-secretase but not epsilon-secretase activity. Nature 440 : 1208-1212

Churcher I, Beher D (2005) Gamma-secretase as a therapeutic target for the treatment of Alzheimer's disease. Curr Phamaceut Design 11: 3363-3382

Cupers P, Bentahir M, Craessaerts K, Orlans I, Vanderstichele H, Saftig P, De Strooper B, Annaert W (2001) The discrepancy between presenilin subcellular localization and $\gamma$-secretase processing of amyloid precursor protein. J Cell Biol 154: 731-740 
Edbauer D, Winkler E, Regula JT, Pesold B, Steiner H, Haass C (2003) Reconstitution of $\gamma$-secretase activity. Nature Cell Biol 5: 486-488

Feng L, Yan H, Wu Z, Yan N, Wang Z, Jeffrey PD, Shi Y (2007) Structure of a site-2 protease family intramembrane metalloprotease. Science 318: 1608-1612

Fluhrer R, Grammer G, Israel L, Condron MM, Haffner C, Friedmann E, Bohland C, Imhof A, Martoglio B, Teplow DB, Haass C (2006) A gamma-secretase-like intramembrane cleavage of TNFalpha by the GxGD aspartyl protease SPPL2b. Nature Cell Biol 8: 894-896

Fluhrer R, Steiner H, Haass C (2008) Intramembrane Proteolysis by gamma-Secretase and related GxGD-type Aspartylproteases.J Biol Chem, in press

Francis R, McGrath G, Zhang J, Ruddy DA, Sym M, Apfeld J, Nicoll M, Maxwell M, Hai B, Ellis MC, Parks AL, Xu W, Li J, Gurney M, Myers RL, Himes CS, Hiebsch RD, Ruble C, Nye JS, Curtis D (2002) aph-1 and pen-2 are required for Notch pathway signaling, $\gamma$-secretase cleavage of $\beta$ APP, and presenilin protein accumulation. Dev Cell 3: 85-97

Friedmann E, Lemberg MK, Weihofen A, Dev KK, Dengler U, Rovelli G, Martoglio B (2004) Consensus analysis of signal peptide peptidase and homologous human aspartic proteases reveals opposite topology of catalytic domains compared with presenilins. JBbiol Chem 279: 50790-50798

Friedmann E, Hauben E, Maylandt K, Schleeger S, Vreugde S, Lichtenthaler SF, Kuhn PH, Stauffer D, Rovelli G, Martoglio B (2006) SPPL2a and SPPL2b promote intramembrane proteolysis of TNFalpha in activated dendritic cells to trigger IL-12 production. Nature Cell Biol 8: 843-848

Gearing AJ, Beckett P, Christodoulou M, Churchill M, Clements J, Davidson AH, Drummond AH, Galloway WA, Gilbert R, Gordon JL, Leber TM, Mangan M, Miller K, Nayee P, Owen K, Patel S, Thomas W, Wells G, Wood LM, Wooley K (1994) Processing of tumour necrosis factor-alpha precursor by metalloproteinases. Nature 370: 555-557

Gordon WR, Vardar-Ulu D, Histen G, Sanchez-Irizarry C, Aster JC, Blacklow SC (2007) Structural basis for autoinhibition of Notch. Nature Struct Mol Biol 14: 295-300

Goutte C, Tsunozaki M, Hale VA, Priess JR (2002) APH-1 is a multipass membrane protein essential for the Notch signaling pathway in Caenorhabditis elegans embryos. Proc Natl Acad Sci USA 99: 775-779.

Haass C (2004) Take five-BACE and the $\gamma$-secretase quartet conduct Alzheimer's amyloid $\beta$-peptide generation. EMBO J 23: 483-488

Haass C, Selkoe DJ (2007) Soluble protein oligomers in neurodegeneration: lessons from the Alzheimer's amyloid beta-peptide. Nature Rev Mol Cell Biol 8: 101-112

Haass C, Steiner H (2002) Alzheimer disease $\gamma$-secretase: a complex story of GxGD-type presenilin proteases. Trends Cell Biol 12: 556-562

Haass C, Hung AY, Schlossmacher MG, Teplow DB, Selkoe DJ (1993) beta-Amyloid peptide and a 3-kDa fragment are derived by distinct cellular mechanisms. J Biol Chem 268: 3021-3024

Hardy J, Selkoe DJ (2002) The amyloid hypothesis of Alzheimer's disease: progress and problems on the road to therapeutics. Science 297: 353-356

Hasegawa H, Sanjo N, Chen F, Gu YJ, Shier C, Petit A, Kawarai T, Katayama T, Schmidt SD, Mathews PM, Schmitt-Ulms G, Fraser PE, St George-Hyslop P (2004) Both the sequence and length of the $\mathrm{C}$ terminus of PEN-2 are critical for intermolecular interactions and function of presenilin complexes. J Biol Chem 279: 46455-46463

Hooper NM, Karran EH, Turner AJ (1997) Membrane protein secretases. Biochem J 321 (Pt 2): 265-279

Iben LG, Olson RE, Balanda LA, Jayachandra S, Robertson BJ, Hay V, Corradi J, Prasad CV, Zaczek R, Albright CF, Toyn JH (2007) Signal peptide peptidase and gamma-secretase share equivalent inhibitor binding pharmacology. J Biol Chem 282: 36829-36836

Kaether C, Lammich S, Edbauer D, Ertl M, Rietdorf J, Capell A, Steiner H, Haass C (2002) Presenilin-1 affects trafficking and processing of betaAPP and is targeted in a complex with nicastrin to the plasma membrane. J Cell Biol 158: 551-561

Kaether C, Capell A, Edbauer D, Winkler E, Novak B, Steiner H, Haass C (2004) The presenilin Cterminus is required for ER-retention, nicastrin-binding and gamma-secretase activity. EMBO J 23: 4738-4748 
Kaether C, Scheuermann J, Fassler M, Zilow S, Shirotani K, Valkova C, Novak B, Kacmar S, Steiner H, Haass C (2007) Endoplasmic reticulum retention of the gamma-secretase complex component Pen2 by Rer1. EMBO Rep 8: 743-748

Kirkin V, Cahuzac N, Guardiola-Serrano F, Huault S, Luckerath K, Friedmann E, Novac N, Wels WS, Martoglio B, Hueber AO, Zornig M (2007) The Fas ligand intracellular domain is released by ADAM10 and SPPL2a cleavage in T-cells. Cell Death Differentiation 14: 1678-1687

Kopan R, Ilagan MX (2004) Gamma-secretase: proteasome of the membrane? Nature Rev Mol Cell Biol 5: 499-504

Kornilova AY, Bihel F, Das C, Wolfe MS (2005) The initial substrate-binding site of gammasecretase is located on presenilin near the active site. Proc Natl Acad Sci USA102: 3230-3235

Krawitz P, Haffner C, Fluhrer R, Steiner H, Schmid B, Haass C (2005) Differential localization and identification of a critical aspartate suggest non-redundant proteolytic functions of the presenilin homologues SPPL2b and SPPL3. J Biol Chem 280: 39515-39523

Kriegler M, Perez C, DeFay K, Albert I, Lu SD (1988) A novel form of TNF/cachectin is a cell surface cytotoxic transmembrane protein: ramifications for the complex physiology of TNF. Cell 53: 45-53

LaPointe CF, Taylor RK (2000) The type 4 prepilin peptidases comprise a novel family of aspartic acid proteases. J Biol Chem 275: 1502-1510

Lazarov VK, Fraering PC, Ye W, Wolfe MS, Selkoe DJ, Li H (2006) From the Cover: Electron microscopic structure of purified, active \{gamma $\}$-secretase reveals an aqueous intramembrane chamber and two pores. Proc Natl Acad Sci USA 103: 6889-6894

Lemberg MK, Martoglio B (2002) Requirements for signal peptide peptidase-catalyzed intramembrane proteolysis. Mol Cell 10: 735-744

Lemberg MK, Freeman M (2007) Functional and evolutionary implications of enhanced genomic analysis of rhomboid intramembrane proteases. Genome Res 17: 1634-1646

Lemieux MJ, Fischer SJ, Cherney MM, Bateman KS, James MN (2007) The crystal structure of the rhomboid peptidase from Haemophilus influenzae provides insight into intramembrane proteolysis. Proc Natl Acad Sci USA104: 750-754

Locksley RM, Killeen N, Lenardo MJ (2001) The TNF and TNF receptor superfamilies: integrating mammalian biology. Cell 104: 487-501

Martin L, Fluhrer R, Reiss K, Kremmer E, Saftig P, Haass C (2008) Regulated intramembrane proteolysis of Bri2 (Itm2b) by ADAM10 and SPPL2a/SPPL2b. J Biol Chem 283: 1644-1652

McGeehan GM, Becherer JD, Bast RC, Jr., Boyer CM, Champion B, Connolly KM, Conway JG Furdon P, Karp S, Kidao S, et al. (1994) Regulation of tumour necrosis factor-alpha processing by a metalloproteinase inhibitor. Nature 370: 558-561

Miklossy J, Taddei K, Suva D, Verdile G, Fonte J, Fisher C, Gnjec A, Ghika J, Suard F, Mehta PD, McLean CA, Masters CL, Brooks WS, Martins RN (2003) Two novel presenilin-1 mutations (Y256S and Q222H) are associated with early-onset Alzheimer's disease. Neurobiol Aging 24: $655-662$

Munter LM, Voigt P, Harmeier A, Kaden D, Gottschalk KE, Weise C, Pipkorn R, Schaefer M, Langosch D, Multhaup G (2007) GxxxG motifs within the amyloid precursor protein transmembrane sequence are critical for the etiology of Abeta42. EMBO J 26: 1702-1712

Nyborg AC, Jansen K, Ladd TB, Fauq A, Golde TE (2004a) A signal peptide peptidase (SPP) reporter activity assay based on the cleavage of type II membrane protein substrates provides further evidence for an inverted orientation of the SPP active site relative to presenilin. J Biol Chem 279: 43148-43156

Nyborg AC, Kornilova AY, Jansen K, Ladd TB, Wolfe MS, Golde TE (2004b) Signal peptide peptidase forms a homodimer that is labeled by an active site-directed gamma-secretase inhibitor J Biol Chem 279: 15153-15160

Ponting CP, Hutton M, Nyborg A, Baker M, Jansen K, Golde TE (2002) Identification of a novel family of presenilin homologues. Human Mol Genet 11: 1037-1044

Prokop S, Shirotani K, Edbauer D, Haass C, Steiner H (2004) Requirement of PEN-2 for stabilization of the presenilin $\mathrm{N}$-/C-terminal fragment heterodimer within the gamma-secretase complex. J Biol Chem 279: 23255-23261 
Qi-Takahara Y, Morishima-Kawashima M, Tanimura Y, Dolios G, Hirotani N, Horikoshi Y, Kametani F, Maeda M, Saido TC, Wang R, Ihara Y (2005) Longer forms of amyloid beta protein: implications for the mechanism of intramembrane cleavage by gamma-secretase. J Neurosci 25: 436-445

Rawson RB, Zelenski NG, Nijhawan D, Ye J, Sakai J, Hasan MT, Chang TY, Brown MS, Goldstein JL (1997) Complementation cloning of S2P, a gene encoding a putative metalloprotease required for intramembrane cleavage of SREBPs. Mol Cell 1: 47-57.

Sato T, Nyborg AC, Iwata N, Diehl TS, Saido TC, Golde TE, Wolfe MS (2006) Signal peptide peptidase: biochemical properties and modulation by nonsteroidal antiinflammatory drugs. Biochemistry 45: 8649-8656

Sato T, Diehl TS, Narayanan S, Funamoto S, Ihara Y, De Strooper B, Steiner H, Haass C, Wolfe MS (2007) Active gamma-secretase complexes contain only one of each component. J Biol Chem 282: 33985-33993

Schlondorff J, Blobel CP (1999) Metalloprotease-disintegrins: modular proteins capable of promoting cell-cell interactions and triggering signals by protein-ectodomain shedding. J Sell Sci 112 (Pt 21): 3603-3617

Selkoe D, Kopan R (2003) Notch and Presenilin: regulated intramembrane proteolysis links development and degeneration. Annu Rev Neurosci 26: 565-597

Shah S, Lee SF, Tabuchi K, Hao YH, Yu C, LaPlant Q, Ball H, Dann CE, 3rd, Sudhof T, Yu G (2005) Nicastrin functions as a gamma-secretase-substrate receptor. Cell 122: 435-447

Steiner H, Kostka M, Romig H, Basset G, Pesold B, Hardy J, Capell A, Meyn L, Grim MG, Baumeister R, Fechteler K, Haass C (2000) Glycine 384 is required for presenilin-1 function and is conserved in polytopic bacterial aspartyl proteases. Nature Cell Biol 2: 848-851

Steiner H, Than M, Bode W, Haass C (2006) Pore-forming scissors? A first structural glimpse of gamma-secretase. Trends Biochem Sci 31: 491-493

Takahashi Y, Hayashi I, Tominari Y, Rikimaru K, Morohashi Y, Kan T, Natsugari H, Fukuyama T, Tomita T, Iwatsubo T (2003) Sulindac sulfide is a noncompetitive gamma-secretase inhibitor that preferentially reduces Abeta 42 generation. J Biol Chem 278: 18664-18670

Thinakaran G, Borchelt DR, Lee MK, Slunt HH, Spitzer L, Kim G, Ratovitsky T, Davenport F, Nordstedt C, Seeger M, Hardy J, Levey AI, Gandy SE, Jenkins NA, Copeland NG, Price DL, Sisodia SS (1996) Endoproteolysis of presenilin 1 and accumulation of processed derivatives in vivo. Neuron 17: 181-190

Tsachaki M, Ghiso J, Rostagno A, Efthimiopoulos S (2008) BRI2 homodimerizes with the involvement of intermolecular disulfide bonds. Neurobiol Aging, in press

Vassalli P (1992) The pathophysiology of tumor necrosis factors. Ann Rev Immunol 10: 411-452

Vetrivel KS, Zhang X, Meckler X, Cheng H, Lee S, Gong P, Lopes KO, Chen Y, Iwata N, Yin KJ, Lee JM, Parent AT, Saido TC, Li YM, Sisodia SS, Thinakaran G (2008) Evidence that CD147 modulation of Abeta levels is mediated by extracellular degradation of secreted Abeta. J Biol Chem, in press

Wang J, Beher D, Nyborg AC, Shearman MS, Golde TE, Goate A (2006a) C-terminal PAL motif of presenilin and presenilin homologues required for normal active site conformation. J Neurochem 96: 218-227

Wang Y, Zhang Y, Ha Y (2006b) Crystal structure of a rhomboid family intramembrane protease. Nature 444: 179-180

Weggen S, Eriksen JL, Das P, Sagi SA, Wang R, Pietrzik CU, Findlay KA, Smith TE, Murphy MP, Bulter T, Kang DE, Marquez-Sterling N, Golde TE, Koo EH (2001) A subset of NSAIDs lower amyloidogenic Abeta42 independently of cyclooxygenase activity. Nature 414: 212-216

Weihofen A, Martoglio B (2003) Intramembrane-cleaving proteases: controlled liberation of functional proteins and peptides from membranes. Trends Cell Biol 13: 71-78

Weihofen A, Binns K, Lemberg MK, Ashman K, Martoglio B (2002) Identification of signal peptide peptidase, a presenilin-type aspartic protease. Science 296: 2215-2218

Weihofen A, Lemberg MK, Friedmann E, Rueeger H, Schmitz A, Paganetti P, Rovelli G, Martoglio B (2003) Targeting presenilin-type aspartic protease signal peptide peptidase with gamma-secretase inhibitors. J Biol Chem 278: 16528-16533 
Wolfe MS, Kopan R (2004) Intramembrane proteolysis: theme and variations. Science 305: 1119 1123

Wolfe MS, Xia W, Ostaszewski BL, Diehl TS, Kimberly WT, Selkoe DJ (1999) Two transmembrane aspartates in presenilin-1 required for presenilin endoproteolysis and $\gamma$-secretase activity. Nature 398: 513-517

Wu Z, Yan N, Feng L, Oberstein A, Yan H, Baker RP, Gu L, Jeffrey PD, Urban S, Shi Y (2006) Structural analysis of a rhomboid family intramembrane protease reveals a gating mechanism for substrate entry. Nature Struct Mol Biol 13: 1084-1091

Yamasaki A, Eimer S, Okochi M, Smialowska A, Kaether C, Baumeister R, Haass C, Steiner H (2006) The GxGD motif of presenilin contributes to catalytic function and substrate identification of gamma-secretase. J Neurosci 26: 3821-3828

Ye J, Rawson RB, Komuro R, Chen X, Dave UP, Prywes R, Brown MS, Goldstein JL (2000) ER stress induces cleavage of membrane-bound ATF6 by the same proteases that process SREBPs. Mol Cell 6: 1355-1364.

Yu G, Nishimura M, Arawaka S, Levitan D, Zhang L, Tandon A, Song YQ, Rogaeva E, Chen F, Kawarai T, Supala A, Levesque L, Yu H, Yang DS, Holmes E, Milman P, Liang Y, Zhang DM, Xu DH, Sato C, Rogaev E, Smith M, Janus C, Zhang Y, Aebersold R, Farrer LS, Sorbi S, Bruni A, Fraser P, St George-Hyslop P (2000) Nicastrin modulates presenilin-mediated notch/glp-1 signal transduction and $\beta$ APP processing. Nature 407: 48-54.

Zhou S, Zhou H, Walian PJ, Jap BK (2005) CD147 is a regulatory subunit of the gamma-secretase complex in Alzheimer's disease amyloid beta-peptide production. Proc Natl Acad Sci USA102: 7499-7504 